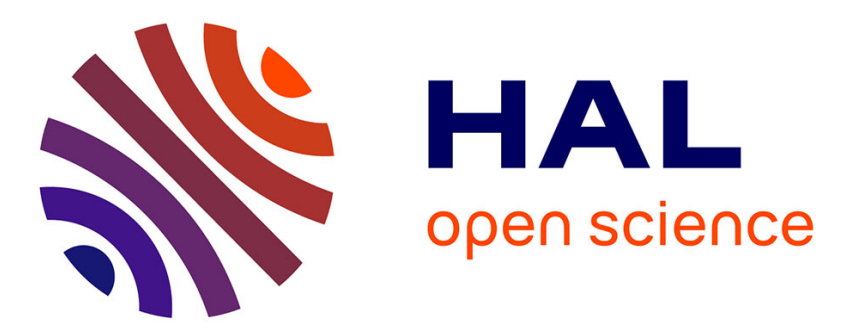

\title{
The protein turnover of Arabidopsis BPM1 is involved in regulation of flowering time and abiotic stress response
}

Andreja Škiljaica, Esther Lechner, Mateja Jagić, Kristina Majsec, Nenad Malenica, Pascal Genschik, Natasa Bauer

\section{- To cite this version:}

Andreja Škiljaica, Esther Lechner, Mateja Jagić, Kristina Majsec, Nenad Malenica, et al.. The protein turnover of Arabidopsis BPM1 is involved in regulation of flowering time and abiotic stress response. Plant Molecular Biology, 2020, 102 (4-5), pp.359-372. 10.1007/s11103-019-00947-2 . hal-03041478

\author{
HAL Id: hal-03041478 \\ https://hal.science/hal-03041478
}

Submitted on 4 Dec 2020

HAL is a multi-disciplinary open access archive for the deposit and dissemination of scientific research documents, whether they are published or not. The documents may come from teaching and research institutions in France or abroad, or from public or private research centers.
L'archive ouverte pluridisciplinaire HAL, est destinée au dépôt et à la diffusion de documents scientifiques de niveau recherche, publiés ou non, émanant des établissements d'enseignement et de recherche français ou étrangers, des laboratoires publics ou privés. 


\title{
Arabidopsis BPM1 protein regulates flowering time and abiotic stress response
}

\author{
${ }^{a}$ Andreja Škiljaica, ${ }^{b}$ Esther Lechner, a Mateja Jagić, ${ }^{a}$ Kristina Majsec, ${ }^{a}$ Nenad Malenica, ${ }^{b}$ Pascal Genschik, \\ a*Natasa Bauer \\ ${ }^{a}$ Division of Molecular Biology, Faculty of Science, University of Zagreb, Horvatovac 102a, 10000 Zagreb, \\ CROATIA; ${ }^{b}$ Institut de Biologie Moléculaire des Plantes, Unité Propre de Recherche 2357, Conventioné \\ avec l'Université de Strasbourg, Strasbourg, FRANCE
}

\section{*Corresponding author \\ natasa.bauer@biol.pmf.hr}

Tel. +38514606263

\section{Key massage}

The environmental conditions regulate plant growth and development. Here the impact of environment on BPM1 protein stability and the role of BPM1 in flowering time and abiotic stress is presented.

\begin{abstract}
A small family of six MATH-BTB genes (BPM1-6) is described in Arabidopsis thaliana. BPM proteins are part of the Cullin E3 ubiquitin ligase complexes and are known to bind three families of transcription factors: ERF/AP2 class I, homeobox-leucine zipper and R2R3 MYB. By targeting these transcription factors for ubiquitination and subsequent proteasomal degradation, BPMs play an important role in plant flowering, seed development and abiotic stress response. In this study, we generated BPM1overexpressing plants that showed an early flowering phenotype, resistance to abscisic acid and tolerance to osmotic stress. We analyzed BPM1-GFP protein stability in overexpressing lines and found that BPM1 protein has high turnover rate and is degraded by proteasome $26 \mathrm{~S}$ in a Cullin-dependent manner. Finally, we found that BPM1 protein stability is environmentally conditioned. Darkness and salt stress triggered BPM1 degradation, whereas elevated temperature enhanced BPM1 stability and accumulation in planta.
\end{abstract}

Key words: MATH-BTB; Early flowering; Water deprivation; ABA, Abiotic stress; Elevated temperature

Acknowledgements: This work was financially supported by University of Zagreb, Croatia and Croatian science foundation (project PHYTOMETHDEV) and LABEX: ANR-10-LABX-0036_NETRNA to E.L. and P.G. 


\section{INTRODUCTION}

The addition of ubiquitin is a common posttranslational modification that controls the stability, function or subcellular localization of many proteins and has important regulatory roles in different cellular and physiological processes (Chen and Hellmann 2013). Cullin-based ubiquitin ligases are modular ubiquitin ligases that control selective protein turnover in eukaryotic cells (Petroski and Deshaies 2005; Hua and Vierstra 2011). They contain three major elements - a Cullin scaffold, a RING finger protein that recruits an ubiquitin-charged E2 enzyme, and a substrate adaptor that places substrates in proximity to the E2 enzyme to facilitate ubiquitin transfer. In Arabidopsis there are six Cullin-like proteins CUL1, CUL2, CUL3A, CUL3B, CUL4 and ANAPHASE PROMOTING COMPLEX2 (Choi et al. 2014). Central to formation of an active Cullin-based ubiquitin ligase complex (except for ANAPHASE PROMOTING COMPLEX2) is neddylation, the modification of a single conserved lysine residue in the Cullin subunit with the NEDD8 protein. Neddylation promotes the structural reorganization of the C-terminal RING binding domain of the Cullin, promoting the processivity of ubiquitin transfer (Duda et al. 2011). MATH-BTB proteins, commonly found in plants and animals, are shown to function as substrate-specific adaptors of Cullin3 (CUL3)-based E3 complexes that facilitate the transfer of ubiquitin moieties to substrates (Weber et al. 2005, Pintard et al. 2003). In Arabidopsis thaliana a small family of six MATH-BTB genes (BPM1-6) is described which codes for at least 16 different proteins (www.uniprot.org; Fig. S1). Arabidopsis BPM proteins bind ERF/AP2 family of transcription factors (TFs), a class I homeobox-leucine zipper TFs, as well as R2R3 MYB family of TFs. By targeting these TFs for ubiquitination and subsequent proteasomal degradation, BPMs play important roles in plant flowering, seed development and abiotic stress responses (Weber and Hellmann 2009, Lechner et al. 2011, Chen et al. 2013, 2015, Morimoto et al. 2017). Besides being important regulators of transcription, BPM proteins were shown to be essential in mediating CUL3 binding to DNA (Chen et al. 2015) and might alter target TFs activity by intervening in their interaction with other cellular components.

There are several T-DNA insertion mutant lines described for each BPM gene (https://www.arabidopsis.org). Many of them are unavailable or described to have expression pattern similar to wild type and, to date, no null mutant was described for any BPM gene. To downregulate the expression of MATH-BTB members, different research groups expressed 35S-driven artificial microRNAs in Arabidopsis, and three types of mutants with downregulated BPMs were recovered: plants expressing 20-50\% of wild type BPM levels (6xami-bpm; Chen et al. 2013), plants with downregulation of BPM 1, 4, 5 and 6 (amiR-bpm; Lechner et al. 2011) and plants with downregulation of BPM1, 2, 3, 4 and 5 
(amiBPM; Morimoto et al. 2017). Each mutant line with downregulated BPMs shows obvious developmental alterations. Moreover, the phenotypes of these mutant lines differ slightly from one another, suggesting specific roles of individual BPM genes.

Relative expression levels and tissue-specific expression patterns of all BPM genes have been analyzed previously (Weber and Hellmann 2009, Lechner et al. 2011) by using PвPM:GUS transgenic lines. The highest BPM1 expression is in buds, flowers, root and leaf vasculature, while semi-quantitative gene expression shows induced BPM1 expression upon salt, osmotic and drought stress (Weber and Hellmann 2009). Here we analyzed the expression pattern of different BPM genes under stress conditions. To examine BPM1 protein and to determine BPM1-specific roles, we produced $A$. thaliana transgenic plants overexpressing GFP-tagged BPM1 under control of the strong $35 S$ promoter. Due to assumed functional redundancy of BPM proteins (Weber and Hellmann 2009), we analyzed the impact of overexpressed BPM1-GFP on expression of native BPM genes. We examined BPM1-GFP subcellular localization and stability, described the developmental features of BPM1-GFP transgenic lines, as well as the abiotic stress response of BPM1-overexpressors.

\section{MATERIALS AND METHODS}

\subsection{Plant Materials and Growth Conditions}

Arabidopsis thaliana (accession Col-0) plants were grown on soil in $16 \mathrm{~h}$ light/ $8 \mathrm{~h}$ dark cycles at $21^{\circ} \mathrm{C}$ and a light intensity of approximately 120 to $130 \mathrm{mmol} / \mathrm{m}^{2} \mathrm{~s}$ with $50 \%$ relative humidity. For germination, seeds were surface sterilized with $1 \%$ Izosan G (100\% sodium dichloroisocyanurate dihydrate, Pliva, Croatia) and $0.01 \%$ Mucasol for $10 \mathrm{~min}$, cold treated at $4{ }^{\circ} \mathrm{C}$ for 2-3 days, and then planted on Murashige and Skoog (MS) medium with $0.8 \%$ agar and $2 \%$ sucrose (germination plates). Plates were incubated in $16 \mathrm{~h}$ light $/ 8 \mathrm{~h}$ dark cycles at $24^{\circ} \mathrm{C}$.

\subsubsection{Stress treatments}

To examine BPM role in stress response, BPM1-overexpressing lines (L003 and L104) and wild type were subjected to different stress conditions. For germination assay surface sterilized seeds were plated on Murashige and Skoog medium supplemented with $0.5 \mathrm{~g}$ MES (MS-MES), $0.8 \%$ agar and $2 \%$ sucrose, and with 25, 50 and $100 \mathrm{mM} \mathrm{NaCl}$; 100, 200 and $300 \mathrm{mM}$ mannitol, or 0.5 and $1 \mu \mathrm{M}$ abscisic acid (ABA). ABA treatments were on MS-MES plates without sucrose. Plates were kept for 3 days at $4{ }^{\circ} \mathrm{C}$ and germination rate (percentage of seeds with radicle emergence) was measured 2 days after transfer to plant growth 
chamber with constant light at $24^{\circ} \mathrm{C}$. For each treatment at least three independent experiments $(n>100)$ were performed. To analyze the effect of ABA on BPMs expression, seeds were germinated on MS-MES plates and 12-day-old seedlings were transferred to liquid MS-MES medium without sucrose and supplemented with $50 \mu \mathrm{M}$ ABA. Solution was vacuum infiltrated into seedlings, and RNA was extracted after 3 hours of incubation at $21^{\circ} \mathrm{C}$. To test the effect of elevated temperature on BPMs expression, seeds were germinated on MS plates and 12-day-old seedlings were incubated in liquid MS medium at $24^{\circ} \mathrm{C}$ or $37^{\circ} \mathrm{C}$ for 3 hours, followed by RNA extraction. To monitor BPM1 protein stability in stress conditions, seeds were germinated on MS-MES plates and 12-day-old seedlings were incubated for 6 hours in liquid MS-MES medium supplemented with $50 \mu \mathrm{M}$ ABA, $150 \mathrm{mM} \mathrm{NaCl}$ or $300 \mathrm{mM}$ mannitol. For ABA treatments, the medium did not contain sucrose. To analyze the effect of light on BPM1 protein stability 12-day-old seedlings were incubated in dark for 14 hours, or to 6 hours light period that followed 8 hours dark period. To monitor temperature-dependent BPM1 stability, seeds were germinated on MS plates and 12-day-old seedlings were, after 8-hours dark period, incubated in the dark at $24^{\circ} \mathrm{C}$ or $37^{\circ} \mathrm{C}$ for 6 hours. For all stability assays, BPM1-GFP signal was monitored by fluorescence microscopy, followed by whole protein extraction, western blotting and immunodetection.

\subsection{Plasmid construction and plant transformation}

Binary vector pB7FWG2-BPM1 was constructed as described by Leljak Levanic et al. (2012), electroporated into Agrobacterium tumefaciens strain GV3101 (pMP90), and then introduced to wild type A. thaliana Col-0 via floral-dip method (Clough and Bent 1998). Transgenic plants were selected on germination plates containing $30 \mathrm{mg} / \mathrm{L}$ glufosinate-ammonium. Selected lines were selfed and T3 or T4 transgenic progeny was used in most experiments.

\subsection{Fluorescence microscopy}

Confocal images were acquired using a Zeiss LSM780 confocal microscope system (Carl Zeiss) or Leica TCS SP2 AOBS. Laser settings for GFP were as follows: excitation $488 \mathrm{~nm}$ / emission: 495-534 nm. Laser settings for propidium iodide were as follows: excitation $543 \mathrm{~nm}$ / emission: 588-695 nm. Images were processed in IMAGEJ (http://rsb.info.nih.gov/ij/).

\subsection{Quantitative reverse transcriptase PCR (RT-qPCR)}

Total RNA for RT-qPCR was extracted with the RNeasy plant mini kit (Qiagen) from of various lines treated or not with $0.2 \mathrm{~g} / \mathrm{L}$ cycloheximide $(\mathrm{CHX}), 50 \mu \mathrm{M} \mathrm{ABA}$, or exposed or not to $37^{\circ} \mathrm{C}$ for 3 hours. 
Total RNA (500 ng) were reverse transcribed with High capacity cDNA reverse transcription kit (ThermoFisher Scientific). For RT-qPCR, cDNA was diluted two times, mixed with GoTaq qPCR Master mix (Promega) and gene-specific primers were added (total volume of $15 \mu \mathrm{l}$ ). All primers used in RT-qPCR are listed in Table S1. PCR was performed on a Lightcycler LC480 apparatus (Roche) or Applied Biosystems 7500 Real-Time PCR System according to the manufacturer's instructions. The mean value of three replicates was normalized to expression of EXP (AT4G26410), and/or TIP4.1 (AT4G34270) genes as internal controls and results were analyzed with delta delta Ct method (Livak and Schmittgen 2001).

\subsection{Protein Gel-Blot analysis}

Whole proteins were extracted from tissues frozen in liquid nitrogen and ground in the mixer mill. One volume of extraction buffer ( $50 \mathrm{mM}$ Tris- $\mathrm{HCl}-\mathrm{pH} 6.8,3 \%$ SDS, $10 \%$ glycerol, $0.1 \%$ bromophenol blue and $2.5 \mathrm{mM}$ DTT) was added and mixed until material thawed. Samples were heated to $95^{\circ} \mathrm{C}$ for $5 \mathrm{~min}$. The extracts were cleared by centrifugation at $14,000 \mathrm{~g}$ for $15 \mathrm{~min}$ and $25^{\circ} \mathrm{C}$. Concentration of proteins was determined by using amido black (Popov et al. 1975). Proteins were analyzed by sodium dodecyl sulfate polyacrylamide gel electrophoresis (SDS-PAGE) in a discontinuous Tris-Gly buffer system using polyacrylamide mini gels (4\% stacking gel and $12 \%$ resolving gel) with the buffer system of Laemmli. For immunoblotting $20 \mu \mathrm{g}$ of proteins per sample was loaded. The proteins were electroblotted at $200 \mathrm{~mA}$ for 120 min onto Immobilon-P polyvinylidene difluoride membrane. The transfer buffer was $20 \mathrm{mM}$ Tris$\mathrm{HCl}, 150 \mathrm{mM}$ glycine, and 10\% methanol. Precision plus protein dual color standard (BioRad) was used. The membrane was blocked with Western Blocker ${ }^{\text {TM }}$ Solution for HRP detection systems (Sigma) for $1 \mathrm{~h}$. The same solution was used for primary (Anti-GFP, Roche) and secondary (anti mouse-HRP, Sigma) antibody dilutions. The blot was incubated with primary antibody at $4{ }^{\circ} \mathrm{C}$ overnight, and with secondary antibody at RT for $2 \mathrm{~h}$. After incubation with antibodies, the membrane was washed 3 times with PBS and signals were detected with chemiluminescence (Luminata Forte Western HRP substrate, Merck) followed by exposure to autoradiographic films (Hyperfilm, Amersham Pharmacia Biotech). Finally, the membrane was stained with $0.1 \%$ Coomassie R-250 in $40 \%$ methanol and $10 \%$ acetic acid, and destained in $40 \%$ methanol and $10 \%$ acetic acid.

\subsection{MG132, MLN4924 and CHX treatments}

For MG132 and MLN4924 treatments, 4-day-old seedlings overexpressing BPM1 germinated on MS germination plates were vacuum infiltrated and incubated for 2 hours in MES buffer (pH 5.7) containing $100 \mu \mathrm{M}$ MG132 or $50 \mu \mathrm{M}$ MLN4924 dissolved in $0.2 \%$ dimethyl sulfoxide (DMSO) or $0.2 \%$ DMSO. After 
incubation, the seedlings were thoroughly washed to remove residual MG132, MLN4924 or DMSO. For confocal monitoring seedlings were immersed in $75 \mu \mathrm{g} / \mathrm{mL}$ propidium iodide and subjected to microscopy. For protein analysis, seedlings were frozen in liquid nitrogen, ground and whole proteins were extracted.

To examine BPM1 protein stability, seedlings were treated with the translational inhibitor $\mathrm{CHX}$ as described by Gilkerson et al. (2016). Seedlings were grown on MS medium for 6 days at $24{ }^{\circ} \mathrm{C}$ and were incubated with $\mathrm{CHX}(0.2 \mathrm{~g} / \mathrm{L})$ for 1 and 3 hours. After sampling, seedlings were frozen in liquid nitrogen, homogenized and whole proteins and RNA were extracted and used for immunoblot analysis and RTqPCR, respectively.

\subsection{Multiple sequence alignments}

For multiple sequence alignments of BTB and MATH domains, sequences of 16 known BPM proteins (www.uniprot.org) were used: BPM1.1 (Q8L765) BPM1.2 (A0A178UFC0), BPM2.1 (AOA1I9LQF8), BPM2.2 (F4JAT1), BPM2.3 (A0A1I9LQF9), BPM2.4 (A0A1I9LQG0), BPM2.5 (A0A178VH59), BPM3.1 (A0A1P8AZW8), BPM3.2 (A0A178W0L2), BPM3.3 (A0A178VZP7), BPM4.1 (Q9SRV1), BPM4.2 (A0A178V9U9), BPM5.1 (Q1EBV6), BPM6.1 (A1L4W5) BPM6.2 (A0A1I9LS60) and BPM6.3 (A0A1I9LS59). The putative MATH and BTB domain sequences were pooled according to Pfam database, aligned using ClustalX v.2.0 (Larkin et al. 2007) and alignments were displayed using GeneDoc v.2.7.

\subsection{Statistical analysis}

Experiments were replicated at least three times on independent samples. Time to bolting, no. of leaves at bolting and germination rate were analyzed by two-tailed T-test between means for wild type and transgenic lines. Differences with a $p$ value of $<0.05$ were regarded as significant.

\section{RESULTS AND DISCUSSION}

\subsection{Diversity of BPM proteins in Arabidopsis}

The Arabidopsis genome comprises six MATH-BTB genes (called BPM1-6) encoding for at least 16 different BPM proteins, according to available databases and represented in Fig. S1A, B. Arabidopsis BPM proteins are presumed to play a role in targeted protein degradation. In this process, the MATH domain recognizes specific substrate proteins whereas the BTB domain binds CUL3 of the E3 ubiquitin ligase complex, which ubiquitinates and thereby designates proteins for proteasomal degradation. Multiple alignments of BPMs amino acid sequences show high similarity (84\% - 100\%) within the MATH domain responsible for substrate recognition (Fig. S1B). This is in accordance with the finding that MATH domain 
recognizes specific amino acid consensus sequence ( $\varphi-\pi-S-X-S / T$ where $\varphi$ is nonpolar; $\pi$ is polar and $X$ is any amino acid) in substrate proteins (Morimoto et al. 2017). However, the BTB domain is marked by surprisingly high variability (30\% - 100\% similarity, Fig. S1A) suggesting that BPM proteins may have additional roles, not only those coupled with CUL3 E3 ligase. One such role could be interaction with proteins outside the Cullin3 pathway.

The BPM1 gene encodes for two proteins, BPM1.1 and BPM1.2. In this work, to generate BPM1overexpressing lines, we used the shorter variant (BPM1.1) which is missing the BPM1.2-specific sequence of 35 amino acids positioned within the BTB domain (Fig. S1C).

\subsection{Regeneration of transgenic Arabidopsis plants with BPM1 overexpression}

Overexpressors of GFP-fused BPM2 and BPM4 (Morimoto et al. 2017), and MYC-fused BPM3 (Lechner et al. 2011) exist, but their phenotype is not described. In addition, three different lines with BPM knockdown have been described to date (Lechner et al. 2011, Chen et al. 2013, Morimoto et al. 2017), and each was shown to possess some unique features, presumably due to uneven downregulation of individual BPM genes. Here, we generated Arabidopsis plants with BPM1-GFP under strong constitutive $35 S$ promoter. Though all primary transformants (T1) expressed full length BPM1-GFP mRNA (Supplementary Fig. S2A), recombinant BPM1-GFP protein was detected by fluorescent microscopy in only two (lines L003 and L104) among more than a hundred T1 lines inspected. Ten transgenic lines (two with visible BPM1-GFP fluorescence, and 8 randomly selected lines without visible GFP signal) were transferred to soil and selfed. All T1 transformants flowered earlier than wild type plants. Two of them did not produce seeds, while all others produced shorter siliques with reduced seed number (Supplementary Fig. S2B). To regenerate homozygotes, plants were selfed and seeds collected.

Occasionally we noticed BPM1-GFP signal in some T2 and T3 seedlings of other lines but since we were not able to detect the BPM1-GFP protein by western blotting these lines were not examined in this study. The lines L003 and L104 (T3 and T4 seed generations), which accumulated BPM1-GFP recombinant protein, were used for all further experiments.

BPM1 overexpression induced early flowering (Table S2, Fig. S2C) and triggered obvious developmental and physiological alterations in transgenic Arabidopsis plants compared to wild type. Plants overexpressing BPM1 had smaller and more compact rosette with leaves that curved counter clockwise, shorter petioles and wider leaf blades that curled under (adaxialized) (Fig. 1A, B). In long day conditions the time to bolting and leaf number at bolting for BPM1 overexpressors were both significantly different from wild type plants (Table S2). The strongest phenotype was in flowers that showed exaggerated 
opening and approach herkogamy where the stigmas were prematurely elongated and positioned above the anthers (Fig. 1B). This spatial separation of male and female reproductive organs is not typical for $A$. thaliana and is most likely the cause of silique shortening and lower seed production in our transgenic lines (Fig. 1B, Fig. S2B). Stigma exsertion was always pronounced in flowers produced immediately after the transition from vegetative to reproductive phase and became less apparent as the plants grew older. Still, overexpressors produced shorter siliques with less seeds or total lack of seed in some siliques. All alterations were more obvious in line L104 than in L003. Shorter siliques are described in the amiR-bpm mutant that together with stigma exsertion have reduced pollen viability (Lechner et al. 2011). Here, by using fluorescein diacetate (Fig. S3), reduced pollen viability was not detected in BPM1 overexpressors. Another BPM knockdown line described by Chen at al. (2013; 6xami-bpm) produce bigger seeds enriched in fatty acids. We considered the seed size of BPM1 overexpressors but noticed no change compared to wild type.

\subsection{Molecular characterization of BPM1-overexpressing plants}

Both BPM1-overexpressing lines (L104 and L003) showed significant increase of BPM1-GFP transcripts relative to endogenous BPM1 transcripts in wild type (Fig. 2A). Line L104 and L003 show 89 and 46 times higher BPM1 expression, respectively. Substantial BPM1 overexpression had no impact on expression of endogenous BPM genes in line L104, while in line L003 expression of endogenous BPM1 gene was significantly reduced (Fig. 2B).

Confocal microscopy and immunodetection showed that BPM1 overexpressing lines do not accumulate the protein in a constitutive manner (Fig. 3A, B, C). The recombinant BPM1-GFP protein was detectable only in stomata, hypocotyl and root of 4-day-old seedlings (Fig. 3A). Consistent with previous results (Lechner et al. 2011, Leljak Levanic et al. 2012, Morimoto et al. 2017), BPM1-GFP localized mainly in the nucleus, except in root elongation zone where it was additionally detected in differentially-sized mobile cytoplasmic particles of unknown origin and function (Online Resource 1). In adult transgenic plants, accumulation of recombinant BPM1-GFP protein resembled endogenous BPM1 gene expression pattern (Weber and Hellmann 2009, Lechner et al. 2011), showing highest abundance in siliques, flowers, and cauline leaves (Fig. 3C). Thus, according high transgene expression and limited GFP fusion protein presence, we assumed tight regulation of BPM1 protein steady state levels. Similar to previously published results (Lechner et al. 2011), we had difficulty detecting BPM protein in planta, which implied their instability. 
To test BPM1 protein stability in vivo, transgenic seedlings were treated with the protein synthesis inhibitor cycloheximide (CHX) and BPM1-GFP protein levels were assessed by western analysis. Untreated seedlings were used as control. CHX effectively inhibited de novo synthesis of BPM1 (Fig. 3D). One hour after $\mathrm{CHX}$ addition, BPM1 was not anymore detectable, thus confirming a high turnover rate of the protein.

To test whether BPM1 is a target of the ubiquitin proteasome pathway, transgenic seedlings were treated with the proteasome inhibitor MG132 and Cullin neddylation inhibitor MLN4924 (Palombella et al. 1994, Hakenjos et al. 2011). In transgenic lines L003 and L104 both inhibitors noticeably induced accumulation of BPM1-GFP (Fig. 4), with stronger effect observed for the Cullin neddylation inhibitor MLN4924. This indicates an important role of proteasome 26S and Cullin E3 ligase in BPM1 degradation. Still, in transgenic lines with BPM1-GFP overexpression and without detectable recombinant BPM1 protein, treatment with inhibitors could not induce accumulation of BPM1-GFP (Fig. SXX), suggesting that another, jet undiscovered mechanism have the major role in BPM1 degradation. In the future it would be interesting to see whether BPM1 is degraded simultaneously with its ubiquitinated targets in a CUL3-dependent manner, or whether an other E3 ligase targets BPM1 for ubiquitination and subsequent degradation, as well as to reveal jet unknown BPM degradation mechanism.

\subsection{Overexpression of BPM1 contributes to $A B A$ resistance and improves stress tolerance}

The signal transduction pathway governed by ABA regulates early developmental programs such as seed dormancy, germination and seedling growth. Besides these functions, ABA also acts as an important signaling molecule during plant response to environmental stress (Sharp and LeNoble 2002, Zhu 2002, Hubbard et al. 2010) and affects expression of more than 1300 genes mediating dramatic changes in plant physiology (Hoth et al. 2002; Sah et al. 2016). In our study ABA had no influence on expression of BPM genes (Fig. S4A), which reflects the currently available expression data (Genevestigator; EFP Browser) showing very low BPMs expression perturbations during different experimental conditions. Nevertheless, through regulation of HB6 and DREB2A transcription factors, BPMs have been described as important factors in ABA signaling and stress tolerance (Lechner et al. 2011, Morimoto et al. 2017). Therefore, we examined ABA and abiotic stress impact on germination of BPM1 overexpressors. Both BPM1-overexpressing lines (L003 and L104) were germinated on different ABA, NaCl or mannitol concentrations. Compared to wild type, BPM1 overexpressing lines showed postponed germination on MS medium (Fig. S5). However, after 48 hours, the initial delay to protrude a radicle equaled with wild 
type (Fig. S4). Considering this observation, we evaluated influence of different treatments on seed germination two days after imbibition.

BPM1-overexpressing lines germinated on ABA significantly better then wild type. Addition of $1 \mu \mathrm{M} A B A$ reduced wild type seed germination to 23\% while BPM1-overexpressing lines L003 and L104 germinated with $39 \%$ and 58\%, respectively (Fig. 5A). Since overexpression of BPM1 led to ABA hyposensitivity, BPM1 might be considered as possible negative regulator of ABA response during germination.

We further tested germination of BPM1 overexpressors exposed to salt and osmotic stress and found significantly better germination rate of transgenic lines on medium with high osmolarity, but wild typelike sensitivity to salt stress induced by $\mathrm{NaCl}$ (Fig. 5B, C).

Altogether, resistance to ABA during germination and enhanced germination ability upon osmotic stress support a positive role of BPM1 in drought response. This corroborates previous findings showing that lines with downregulated BPMs are more drought-sensitive than wild type (Lechner et al. 2011, Morimoto et al. 2017).

\subsection{Environmental conditions influence BPM1 protein stability}

By mediating proteolysis of different transcription factors BPMs are involved in sensing environmental changes, such as daily rhythm oscillations, temperature fluctuation and abiotic stress (Sakuma et al. 2006; Cernac et al. 2006; Henriksson et al. 2005; Chen et al. 2015). However, nothing is known about the stability of BPM proteins during these external changes. Here we tested BPM1 protein stability during normal daily rhythm ( $16 \mathrm{~h}$ day and $8 \mathrm{~h}$ dark, $24^{\circ} \mathrm{C}$ ), after exposure to $\mathrm{ABA}$, osmotic or salt stress, and at different temperature regimes.

We noticed apparent alteration of BPM1-GFP protein accumulation in seedlings exposed to dark or light. When plantlets were exposed to light, BPM1 protein accumulated in cell nuclei. Incubation of seedlings in the dark resulted in complete BPM1-GFP signal depletion in stomata and hypocotyl cells, while in roots BPM1-GFP seemed to accumulate in root xylem (Fig. 6A). Additionally, western analysis showed consistent accumulation of BPM1 during the day and apparent reduction of BPM1 protein levels in the dark, with BPM1 levels reaching their minimum at the end of the dark period, at 6 a.m. (Fig. 6B). This photoperiod-dependent fluctuation in BPM1 levels nicely corresponds with the previously observed daily oscillations in MYB56 and FT expression. Just opposite to BPM1, MYB56 amount is lowest at the end of photoperiod (6 p.m.) and highest at the beginning of photoperiod, at 8 a.m. (Chen et al. 2015). Furthermore, FT gene expression pattern changes noticeably over the course of the day and is inversely correlated with MYB56 accumulation (Chen et al. 2015, Krzymuski et al. 2015). According to a previously 
proposed model, BPM1 induces the degradation of the transcription inhibitor MYB56, thereby relieving the negative effects of MYB56 on the promoter of the FT gene, a major activator of flowering (Chen et al. 2015). The photoperiod-dependent change in stability of BPM1 observed here further confirms this hypothesis and proposes a role of BPM1 in photoperiod-dependent regulation of flowering. However, the mechanism of BPM1 degradation in the dark remains to be resolved.

We further tested BPM1 protein stability in response to ABA, salt and osmotic stress. Exposure to salt stress for 6 hours caused BPM1 protein depletion, while exposure to mannitol and ABA treatment had no effect on BPM1 levels (Fig. 6C). Interestingly, a correlation was observed between stress conditions where BPM1 overexpressors exhibited higher stress resistance compared to wild type (Fig. 5), and the conditions where high levels of BPM1 protein were measured. As long as BPM1 protein levels were high, BPM1 overexpressors were resistant to stress. Salt stress triggered BPM1 degradation, resulting in reduced stress tolerance in BPM1 overexpressors, and thus suggesting an important role of BPM1 protein turnover in stress response.

Furthermore, we analyzed the effects of elevated temperature on expression of endogenous BPMs and on stability of recombinant BPM1. In wild type plants, RT-qPCR analysis showed that 3 hours of incubation at $37^{\circ} \mathrm{C}$ induced the expression of endogenous BPM1-3, decreased the expression of BPM4, while expression of BPM5 and BPM6 remained unchanged (Fig. S4B). Similar trends were observed in both overexpressor lines under identical experimental conditions (data not shown). It was recently shown that BPM2 forms a complex with DREB2A after exposure to heat (Morimoto et al. 2017). Therefore, the substantial (12-fold) increase in expression of BPM2 caused by elevated temperature in wild type plants could reflect the increase in demand for BPM2, as a negative regulator of DREB2A upon heat stress. Interestingly, we observed some bias regarding expression of BPM1 splicing variants upon elevated temperature, with preferable expression of BPM1.2. This result indicates temperaturedependent regulation of expression and/or splicing of BPM1 and possibly other BPM genes. Namely, the BPM2 gene encodes five splicing variants, all of which were analyzed in our RT-qPCR experiment using a single primer pair. In the future, it would be interesting to see whether changes in environmental temperature influence alternative splicing of BPM2 and to what degree.

Western analysis of transgenic seedlings incubated at $37^{\circ} \mathrm{C}$ showed obvious BPM1 accumulation (Fig. 6D, F). Elevated temperature induced BPM1 accumulation in both light (Fig. 6D) and dark (Fig. 6F) treated seedlings. To exclude the possibility that heat-induced BPM1 accumulation was caused by enhanced transgene expression, we performed RT-qPCR analysis and found that relative mRNA levels of $B P M 1-G F P$ transgene remained unchanged at $37^{\circ} \mathrm{C}$ (Fig. S4C). Therefore, accumulation of BPM1 is most 
likely regulated at the level of protein synthesis and/or degradation. To further test this hypothesis, transgenic seedlings incubated at $24^{\circ} \mathrm{C}$ and $37^{\circ} \mathrm{C}$ were treated with protein synthesis inhibitor CHX (Fig. 6E) and BPM1-GFP protein levels were quantified. Protein synthesis was blocked by CHX and BPM1-GFP was not detectable after one hour at $24^{\circ} \mathrm{C}$. However, when $\mathrm{CHX}$-treated seedlings were incubated at 37 ${ }^{\circ} \mathrm{C}$, the BPM1-GFP signal remained detectable, reflecting enhanced stability of already synthesized BPM1GFP at higher temperatures. Therefore, environmental temperature appears to have an important role in regulating BPM1 protein stability. This is particulary interesting in the context of recent findings where BPM proteins have been described as important factors in plant adaptation to heat stress through interaction with DREB2A (Morimoto et al. 2017). DREB2A is a key transcription factor that controls the response to dehydration and heat stress by activating many stress-inducible target genes. DREB2A expression itself is induced by dehydration or elevated temperature while DREB2A protein degradation on 265 proteasome is mediated by DRIP1/2 and CUL3-BPMs (Morimoto et al. 2013; 2017). During heat stress, DREB2A protein levels are markedly increased immediately after exposure to elevated temperatures, with an apparent drop after a few hours (Morimoto et al. 2013; 2017). BPMs have been shown to recognize and destabilize DREB2A (Morimoto et al. 2017) and the strong heat-induced stabilization of BPM1 shown here might explain the decrease in DREB2A levels several hours into heat response. The stabilization of BPM1 protein could be crucial for regulation of DREB2A transcriptional activity. Firstly, heat-stabilized BPM1 may bind to DREB2A and modulate DREB2A docking on target promoters. Secondly, stabilized BPM1 could induce CUL3-dependent ubiquitination and proteasomal degradation of DREB2A, possibly to prevent damaging effects of excess DREB2A on plant growth. This potential protective role of BPM1 in heat response presents an intriguing topic for further research.

\section{Conclusions}

The 6 BPM genes in the $A$. thaliana genome encode at least 16 different BPM proteins. To better characterize BPM1 protein, transgenic A. thaliana plants overexpressing BPM1-GFP gene were regenerated. BPM1 overexpression induced notable morphological and physiological changes such as earlier flowering, reduced seed production and resistance to $A B A$ and osmotic stress during germination.. Prolonged exposure to heat caused enhanced expression of BPM1-3 genes and influenced BPM1 splicing, protein synthesis and degradation. BPM1 protein stability in planta was affected by environmental conditions. BPM1 molecular mechanism is suggested (Fig. 7) according to which BPM1 is accumulated in plants exposed to light and elevated temperature while during night and in salt stress BPM1 level is reduced. Accumulation of BPM1 may lead to degradation of BPM1 substrate proteins 
MYB56 and DREB2A and influence plant flowering and heat response. It would be interesting to see if BPM1 is degraded simultaneously with its ubiquitinated targets in a CUL3-dependent manner, or whether an other E3 ligase targets BPM1 for ubiquitination and subsequent degradation. Regarding the apparent stabilization of BPM1 upon heat treatment, several questions remain to be answered. Namely, how does the process of BPM1 stabilization occur, how is it regulated and is there a link connecting the environmentally conditioned stability of BPM1 and its role in targeting transcription factors for ubiquitination and proteasomal degradation?

Conflict of Interest: The authors declare that they have no conflict of interest.

\section{REFERENCES}

Cernac A, Andre C, Hoffmann-Benning S, Benning C (2006) WRI1 is required for seed germination and seedling establishment. Plant Physiol. 141(2):745-757.

Chen L, Bernhardt A, Lee J, Hellmann H (2015) Identification of Arabidopsis MYB56 as a novel substrate for CRL3(BPM) E3 ligases. Mol Plant. 8(2):242-250. doi: 10.1016/j.molp.2014.10.004.

Chen L, Hellmann H (2013) Plant E3 ligases: flexible enzymes in a sessile world. Mol Plant. 6(5):13881404. doi: $10.1093 / \mathrm{mp} / \mathrm{sst005}$.

Chen L, Lee JH, Weber H, Tohge T, Witt S, Roje S, Fernie AR, Hellmann H (2013) Arabidopsis BPM proteins function as substrate adaptors to a cullin3-based E3 ligase to affect fatty acid metabolism in plants. Plant Cell. 25(6):2253-2264. doi: 10.1105/tpc.112.107292.

Choi CM, Gray WM, Mooney S, Hellmann H (2014) Composition, roles, and regulation of cullin-based ubiquitin e3 ligases. Arabidopsis Book. 12:e0175. doi: 10.1199/tab.0175.

Clough SJ, Bent AF (1998) Floral dip: a simplified method for Agrobacterium-mediated transformation of Arabidopsis thaliana. Plant J. 16(6):735-743.

Duda DM, Scott DC, Calabrese MF, Zimmerman ES, Zheng N, Schulman BA (2011) Structural regulation of cullin-RING ubiquitin ligase complexes. Curr Opin Struct Biol. 21(2):257-264. doi:

10.1016/j.sbi.2011.01.003.

Gilkerson J, Tam R, Zhang A, Dreher K, Callis J (2016) Cycloheximide assays to measure protein degradation in vivo in plants. Bio-protocol. 6(17): doi: 10.21769/BioProtoc.1919. 
Hakenjos JP, Richter R, Dohmann EM, Katsiarimpa A, Isono E, Schwechheimer C (2011) MLN4924 is an efficient inhibitor of NEDD8 conjugation in plants. Plant Physiol. 156(2):527-536. doi:

10.1104/pp.111.176677.

Henriksson E, Olsson AS, Johannesson H, Johansson H, Hanson J, Engström P, Söderman E (2005) Homeodomain leucine zipper class I genes in Arabidopsis. Expression patterns and phylogenetic relationships. Plant Physiol. 139(1):509-518.

Himmelbach A, Hoffmann T, Leube M, Höhener B, Grill E (2002) Homeodomain protein ATHB6 is a target of the protein phosphatase ABI1 and regulates hormone responses in Arabidopsis. EMBO J. 21(12):302938.

Hoth S, Morgante M, Sanchez JP, Hanafey MK, Tingey SV, Chua NH (2002) Genome-wide gene expression profiling in Arabidopsis thaliana reveals new targets of abscisic acid and largely impaired gene regulation in the abi1-1 mutant. J Cell Sci. 115(Pt 24):4891-900.

Hua Z, Vierstra RD (2011) The cullin-RING ubiquitin-protein ligases. Annu Rev Plant Biol. 62:299-334. doi: 10.1146/annurev-arplant-042809-112256.

Hubbard KE, Nishimura N, Hitomi K, Getzoff ED, Schroeder JI (2010) Early abscisic acid signal transduction mechanisms: newly discovered components and newly emerging questions. Genes Dev. 24(16):1695-

708. doi: 10.1101/gad.1953910.

Krzymuski M, Andrés F, Cagnola JI, Jang S, Yanovsky MJ, Coupland G, Casal JJ (2015) The dynamics of FLOWERING LOCUS T expression encodes long-day information. Plant J. 83(6):952-61. doi:

10.1111/tpj.12938.

Larkin MA, Blackshields G, Brown NP, Chenna R, McGettigan PA, McWilliam H, Valentin F, Wallace IM, Wilm A, Lopez R, Thompson JD, Gibson TJ, Higgins DG (2007) Clustal W and Clustal X version 2.0. Bioinformatics. 23:2947-2948.

Lechner E, Leonhardt N, Eisler H, Parmentier Y, Alioua M, Jacquet H, Leung J, Genschik P (2011) MATH/BTB CRL3 receptors target the homeodomain-leucine zipper ATHB6 to modulate abscisic acid signaling. Dev Cell.21(6):1116-1128. doi: 10.1016/j.devcel.2011.10.018.

Leljak Levanic D, Horvat T, Martinčić J, Bauer N (2012) A novel bipartite nuclear localization signal guides BPM1 protein to nucleolus suggesting its Cullin3 independent function. PLoS One. 7(12):e51184. doi: 10.1371/journal.pone.0051184.

Livak KJ, Schmittgen TD (2001) Analysis of relative gene expression data using real-time quantitative PCR and the 2(-Delta Delta C(T)) Method. Methods. 25(4):402-408.

Morimoto K, Mizoi J, Qin F, Kim JS, Sato H, Osakabe Y, Shinozaki K, Yamaguchi-Shinozaki K (2013) Stabilization of Arabidopsis DREB2A is required but not sufficient for the induction of target genes under conditions of stress. PLoS One. 8(12):e80457. doi: 10.1371/journal.pone.0080457.

Morimoto K, Ohama N, Kidokoro S, Mizoi J, Takahashi F, Todaka D, Mogami J, Sato H, Qin F, Kim JS, Fukao Y, Fujiwara M, Shinozaki K, Yamaguchi-Shinozaki K (2017) BPM-CUL3 E3 ligase modulates 
thermotolerance by facilitating negative regulatory domain-mediated degradation of DREB2A in Arabidopsis. Proc Natl Acad Sci U S A. 114(40):E8528-E8536. doi: 10.1073/pnas.1704189114.

Palombella VJ, Rando OJ, Goldberg AL, Maniatis T (1994) The ubiquitin-proteasome pathway is required for processing the NF-kappa B1 precursor protein and the activation of NF-kappa B. Cell. 78(5):773-785.

Petroski MD, Deshaies RJ (2005) Function and regulation of cullin-RING ubiquitin ligases. Nat Rev Mol Cell Biol. 6(1):9-20.

Pintard L, Willis JH, Willems A, Johnson JL, Srayko M, Kurz T, Glaser S, Mains PE, Tyers M, Bowerman B, Peter M (2003) The BTB protein MEL-26 is a substrate-specific adaptor of the CUL-3 ubiquitin-ligase. Nature. 18;425(6955):311-6.

Popov N, Schmitt M, Schulzeck S, Matthies H (1975) Reliable micromethod for determination of the protein content in tissue homogenates. Acta Biol Med Ger. 34(9):1441-1446.

Sah SK, Reddy KR, Li J (2016) Abscisic Acid and Abiotic Stress Tolerance in Crop Plants. Front Plant Sci. 7:571. doi: 10.3389/fpls.2016.00571.

Sakuma Y, Maruyama K, Qin F, Osakabe Y, Shinozaki K, Yamaguchi-Shinozaki K (2006) Dual function of an Arabidopsis transcription factor DREB2A in water-stress-responsive and heat-stress-responsive gene expression. Proc Natl Acad Sci U S A. 103(49):18822-18827.

Sharp RE, LeNoble ME (2002) ABA, ethylene and the control of shoot and root growth under water stress. J Exp Bot. 53(366):33-37.

Weber H, Bernhardt A, Dieterle M, Hano P, Mutlu A, Estelle M, Genschik P, Hellmann H (2005) Arabidopsis AtCUL3a and AtCUL3b form complexes with members of the BTB/POZ-MATH protein family. Plant Physiol. 37(1):83-93.

Weber H, Hellmann H (2009) Arabidopsis thaliana BTB/ POZ-MATH proteins interact with members of the ERF/AP2 transcription factor family. FEBS J. 276(22):6624-6635. doi: 10.1111/j.1742-

4658.2009.07373.x.

Zhu JK (2002) Salt and drought stress signal transduction in plants. Annu Rev Plant Biol. 53:247-73. 


\section{FIGURE DESCRIPTION}

Figure 1. Overexpression of BPM1 in Arabidopsis thaliana

A) Wild type (WT) plant: rosette phenotype of 8-week-old plant (1), inflorescence $(2,3)$, flower bud (4) and flowers (5) of 12-week-old plant.

B) BPM1-GFP overexpressing line L104: rosette phenotype of 8-week-old plant (6) flower bud (7), flower (8) and inflorescence $(9,10)$ of 12-week-old plant.

\section{Figure 2. BPMs gene expression profile in BPM1-overexpressing lines}

RNA is isolated from 12-day-ols seedlings. Relative expression levels are obtained by quantitative RTqPCR in wild type (COL) and BPM1 overexpressing lines L003 and L104. The data are presented as fold change. Geometric means $\pm S D$ of three replicates are shown. Asterisks indicate statistically significant differences between the BPM1 overexpressing lines and wild type seedlings according to Student's $t$ test, $\mathrm{P}<0.01$.

A) BPM1-GFP overexpression in L104 and L003. Expression of BPM1-GFP is normalized to expression of endogenous BPM1 gene.

B) Relative expression levels of endogenous $B P M 1, B P M 2, B P M 3, B P M 4, B P M 5, B P M 6$ genes. Expression of each endogenous transcript is normalized to wild type expression.

\section{Figure 3. BPM1 protein expression in Arabidopsis thaliana}

For immunodetection, whole protein extracts are immunoblotted with anti-GFP monoclonal antibody (upper panels in B, C, D). For loading control, proteins are stained with Coomassie on PVDF membranes (lower panels in B, C, D).

A) BPM1-GFP protein accumulates in stomata $(1,2)$ hypocotyl $(3)$ and in root (4) of 12-day-old BPM1overexpressing seedlings. Images are obtained by confocal microscopy. Bar is $25 \mu \mathrm{m}$.

B) BPM1 protein accumulation in 12 day-old seedlings. Two biological replicates per overexpression line L003 and L104 are shown.

C) BPM1 protein accumulates in siliques (S) abnormal flowers (aF), normal flowers (F), rosette (R) or cauline (C) leaves of 12-week-old BPM1-overexpressing plants.

D) BPM1 protein turnover in vivo. Six-day-old BPM1-overexpressing seedlings were treated with the protein synthesis inhibitor cycloheximide ( $\mathrm{CHX} ; 0.2 \mathrm{~g} / \mathrm{L})$. The seedlings were harvested before treatment $(0)$ and after 1 and 3 hours. 
Figure 4. The neddylation inhibitor MLN4924 and proteasome inhibitor MG132 stabilize BPM1 protein in planta

Root tips are stained with propidium iodide and subjected to confocal microscopy. Bar is $100 \mu \mathrm{m}$. Fourday-old seedlings of wild-type (COL) or lines overexpressing BPM1-GFP (L003 and L104) are treated for two hours with:

A) $50 \mu \mathrm{M}$ MLN4924, or

B) $100 \mu \mathrm{M}$ MG132.

C) Total proteins are extracted from seedlings treated with $0.2 \%$ DMSO, $50 \mu \mathrm{M}$ MLN4924 or $100 \mu \mathrm{M}$ MG132 and immunoblotted with anti-GFP monoclonal antibody (upper panel). For loading control proteins are stained with Coomassie on PVDF membrane (lower panel).

\section{Figure 5. BPM1 overexpression affect seed germination}

Germination rate (percentage of seeds with radicle emergence) is examined for wild type (COL) and lines with BPM1 overexpression (L104 and L003). Error bars represent standard deviation. * marks significantly different germination rate compared to wild type $(P \leq 0.05)$.

A) BPM1 overexpressors show higher resistance to abscisic acid (ABA) treatment compared to wild type.

B) BPM1 overexpressors show higher resistance to mannitol-induced osmotic stress compared to wild type.

C) BPM1 overexpressors and wild type are equally susceptible to $\mathrm{NaCl}$-induced salt stress.

\section{Figure 6. BPM1 protein stability is regulated by environmental conditions}

For all experiments L104 line was used. Scale bar on A and F is $50 \mu \mathrm{m}$. For immunodetection whole protein extracts are immunoblotted with anti-GFP monoclonal antibody (upper panels in $B, C, D, E$ ). For loading control proteins are stained with Coomassie on PVDF membranes (lower panels in B, C, D, E).

A) BPM1-GFP protein accumulates in root nuclei during light exposure and in xylem during dark exposure. Twelve-day-old seedlings were incubated in dark or exposed $6 \mathrm{~h}$ to light and immediately analyzed by confocal microscopy.

B) BPM1 is degraded during night. Twelve-day-old seedlings were cultivated in $16 \mathrm{~h}$ day / $8 \mathrm{~h}$ night regime with the dark period beginning at 23:00 and ending at 07:00. Seedlings were harvested every four hours.

C) BPM1 protein is degraded after exposure to $\mathrm{NaCl}$-induced salt stress but remains stable after ABA treatment and mannitol-induced osmotic stress. Twelve-day old seedlings were exposed for $6 \mathrm{~h}$ to either $50 \mu \mathrm{M}$ ABA, $150 \mathrm{mM} \mathrm{NaCl}$ or $300 \mathrm{mM}$ mannitol (Man). Untreated seedlings were used as control (0). 
D) Abundant BPM1 accumulation after exposure to $37^{\circ} \mathrm{C}$. Six-day-old seedlings are harvested before treatment (0) and 1 and 3 hours after incubation at $37^{\circ} \mathrm{C}$.

E) BPM1 protein degradation is reduced at $37^{\circ} \mathrm{C}$. Six-day-old seedlings are treated with $\mathrm{CHX}(0.2 \mathrm{mg} / \mathrm{mL})$ and exposed to $24^{\circ} \mathrm{C}$ or $37^{\circ} \mathrm{C}$. The seedlings are harvested before treatment (0) and 1 and 3 hours after treatments.

F) BPM1 protein accumulates in dark at $37^{\circ} \mathrm{C}$. Twelve-day-old seedlings were harvested after $6 \mathrm{~h}$ exposure to $24^{\circ} \mathrm{C}$ or $37^{\circ} \mathrm{C}$ in the dark and immediately analyzed by confocal microscopy.

\section{Figure 7. BPM1 molecular mechanism}

BPM1 is accumulated in plants exposed to light and elevated temperature while during night and in salt stress BPM1 level is reduced. Accumulation of BPM1 may lead to degradation of BPM1 substrate proteins MYB56 and DREB2A and influence plant flowering and heat response. 
a
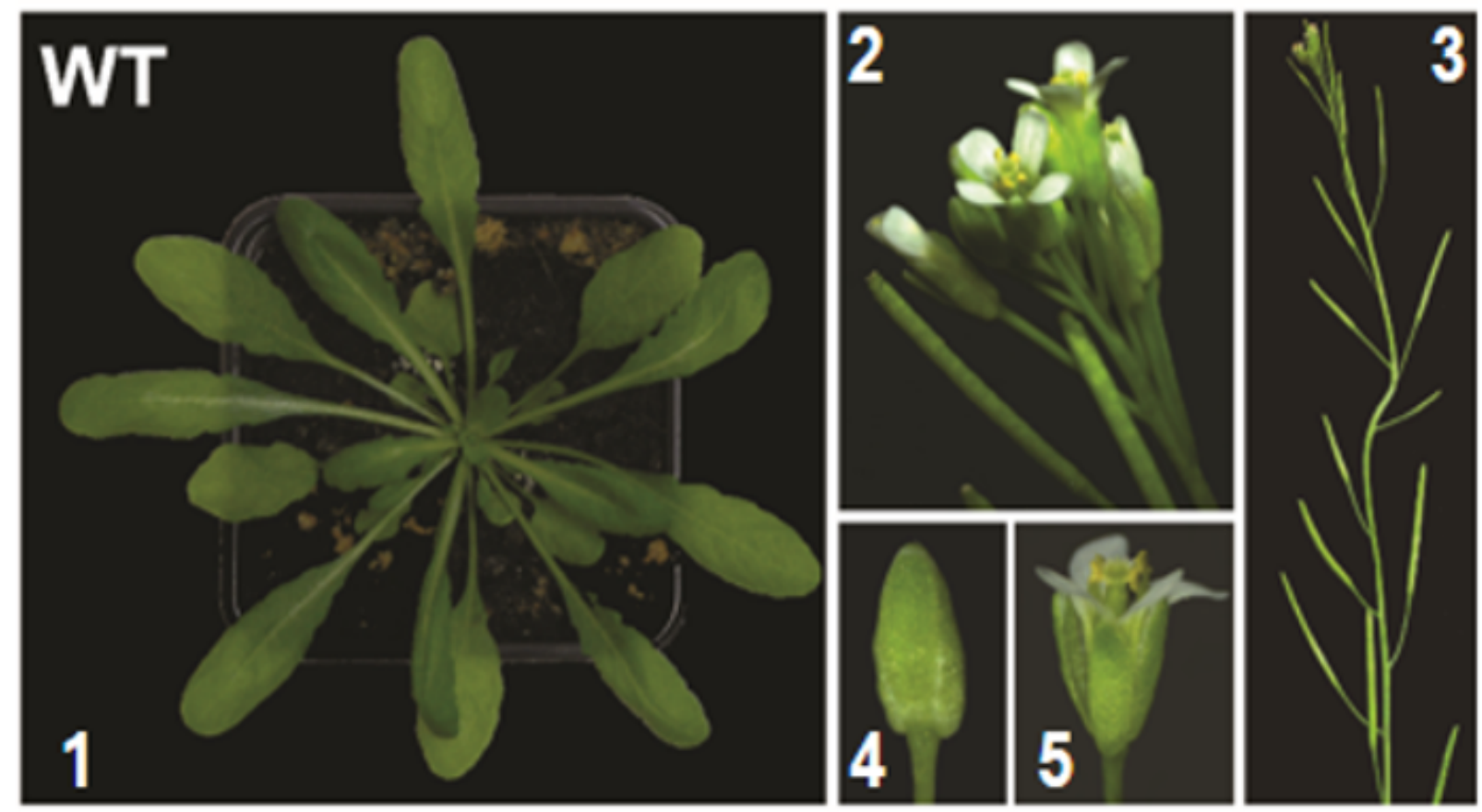

b
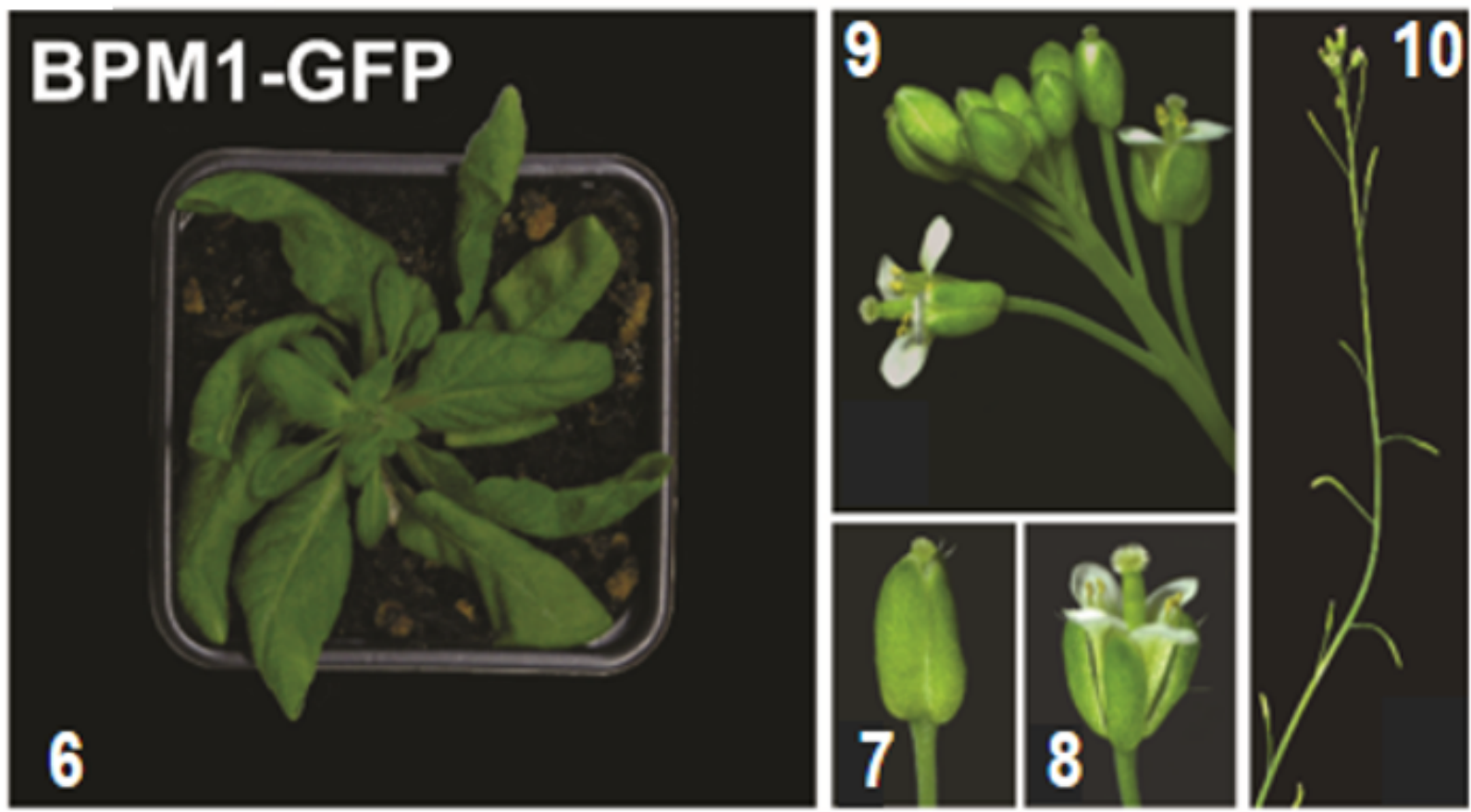

Figure 1. Overexpression of BPM1 in Arabidopsis thaliana 

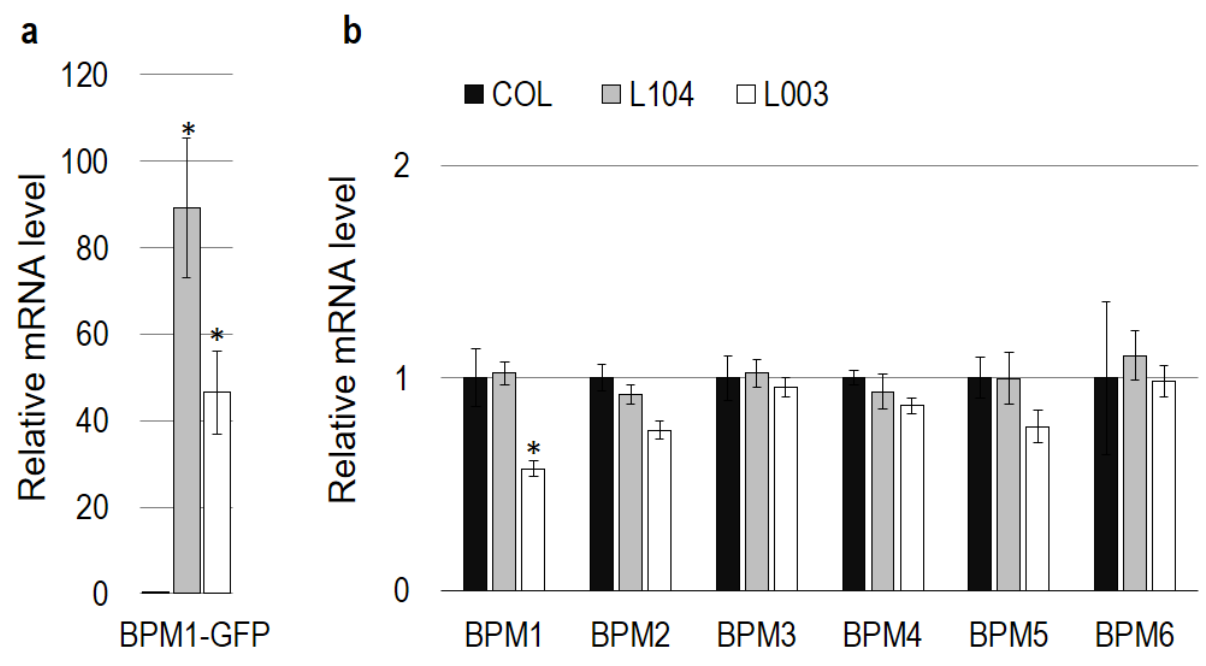

Figure 2. BPMs gene expression profile in BPM1-overexpressing lines 
a
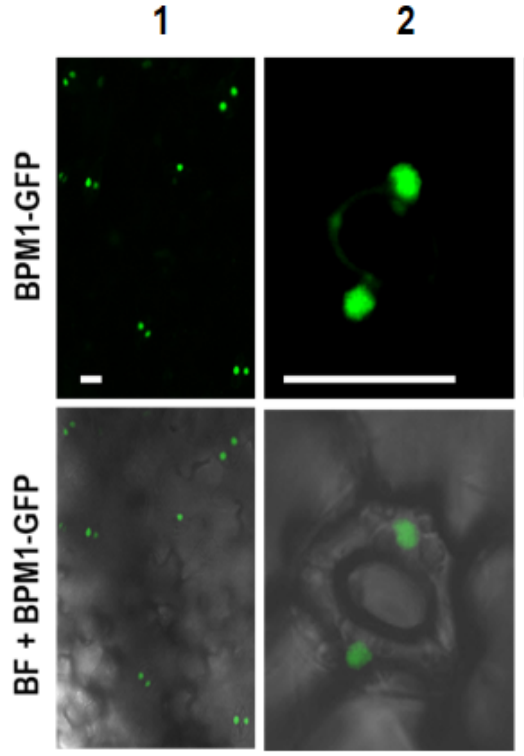

b
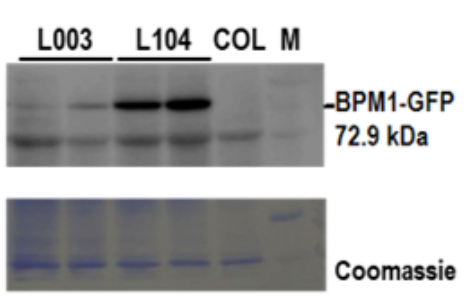

C $\quad \frac{\mathrm{COL}}{\mathrm{F}} \frac{\mathrm{L} 104}{\mathrm{~S} \text { aF F R C }}$

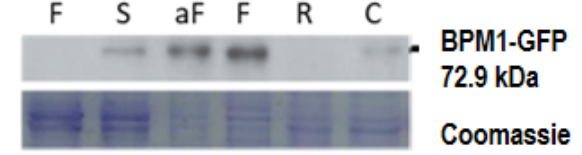

34
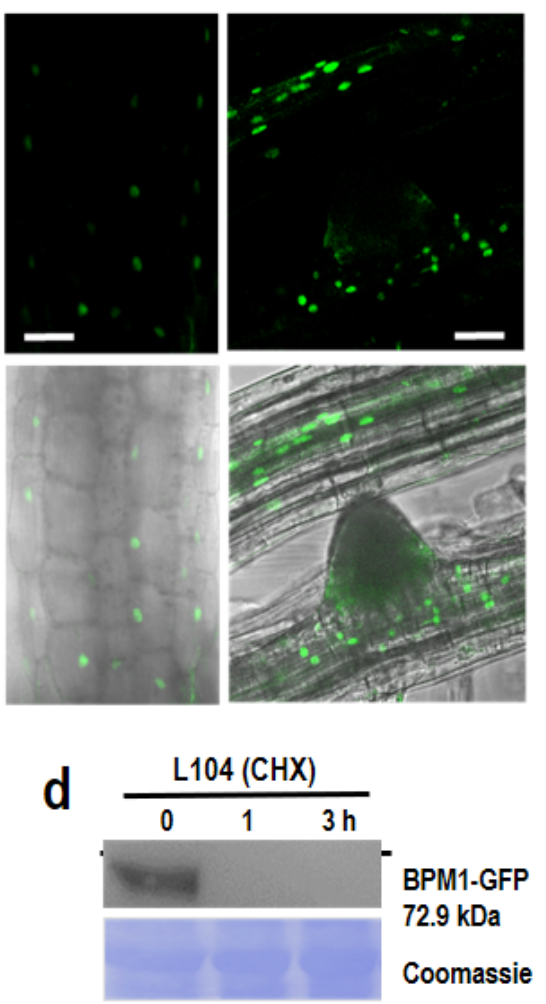

Figure 3. BPM1 protein expression in Arabidopsis thaliana 


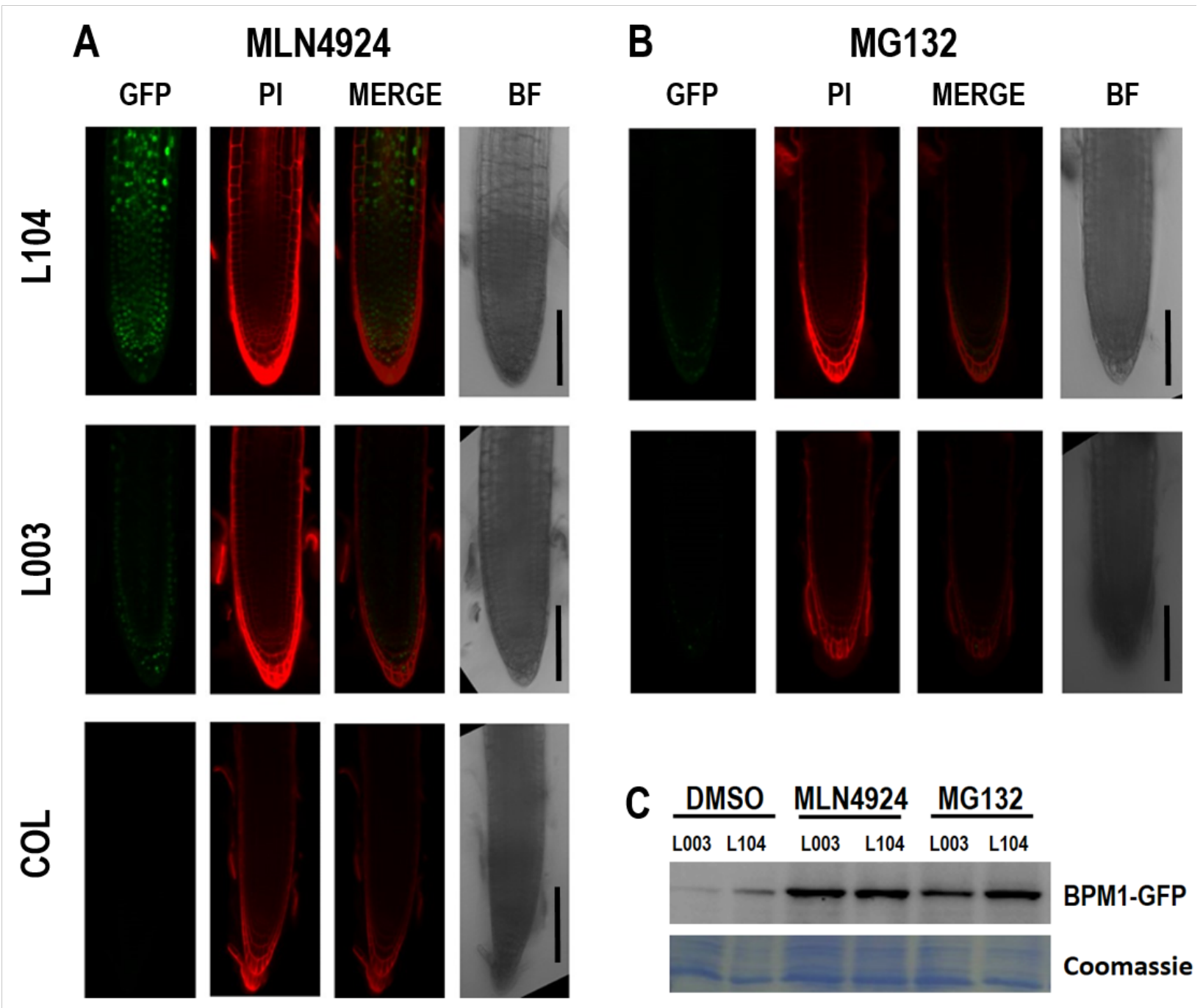

Figure 4. The neddylation inhibitor MLN4924 and proteasome inhibitor MG132 stabilize BPM1 protein in planta. 

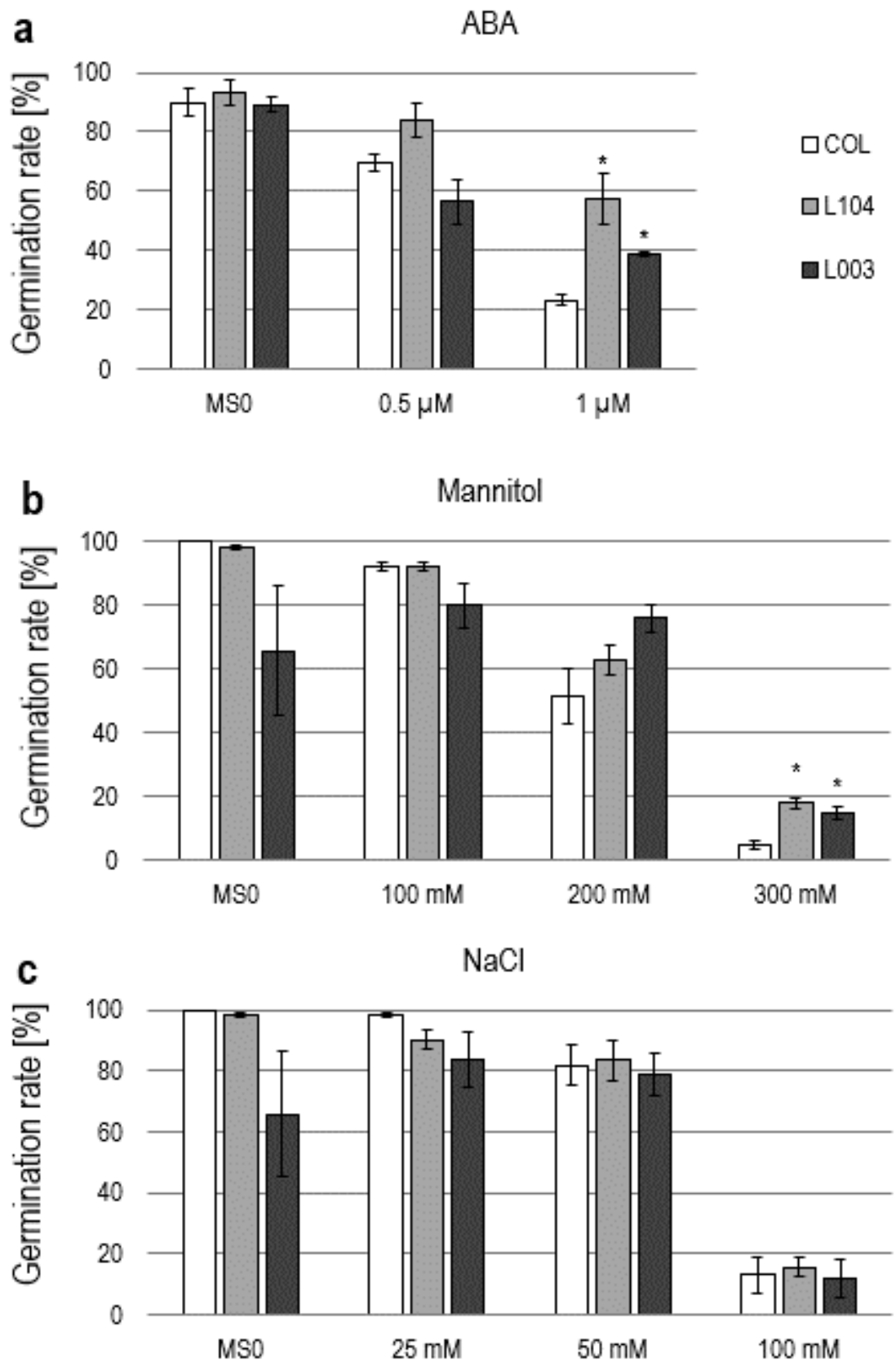

Figure 5. BPM1 overexpression affect seed germination 


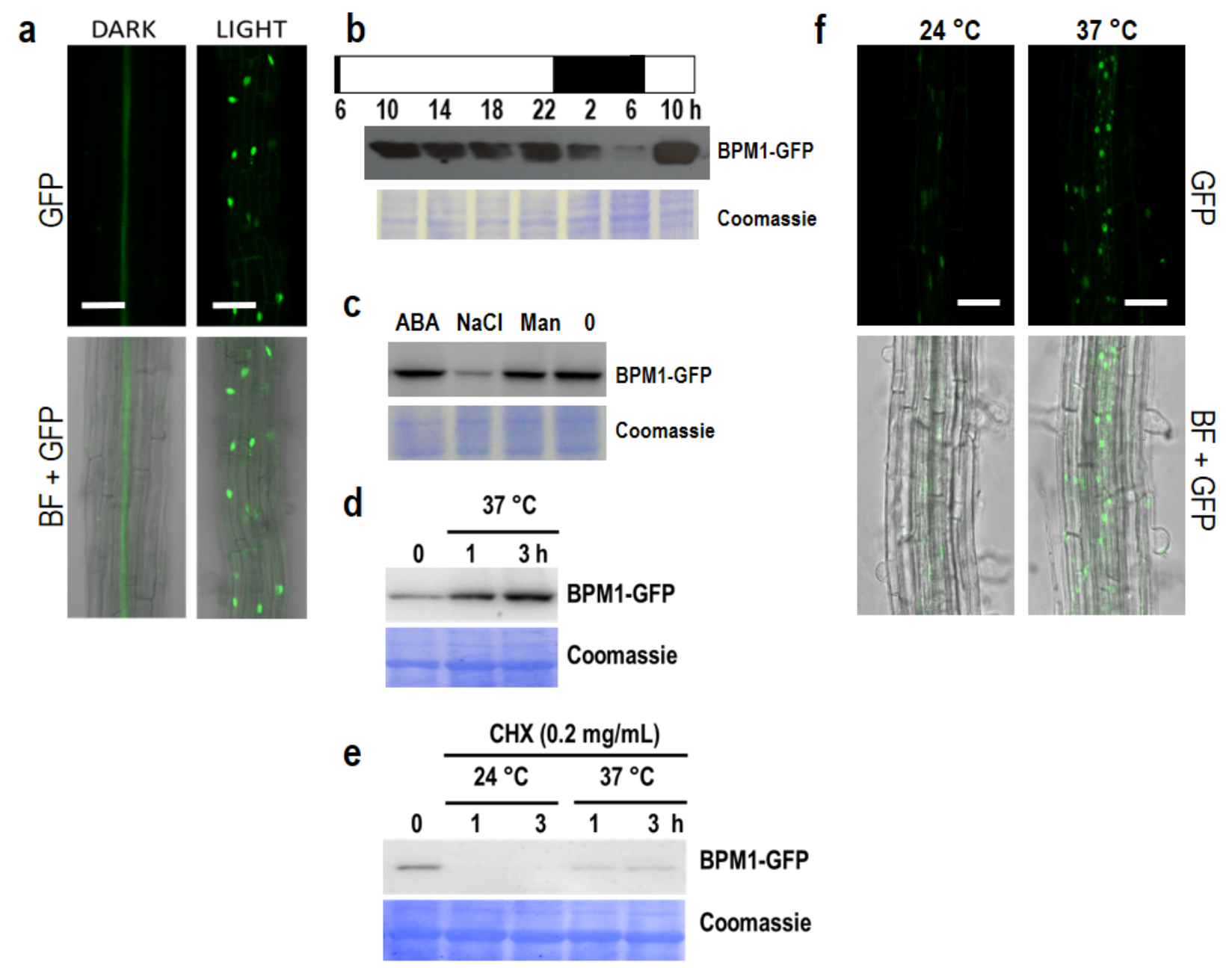

Figure 6. BPM1 protein stability is regulated by environmental conditions 


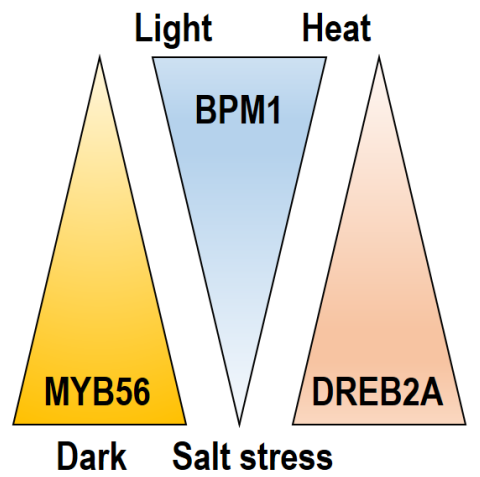

Figure 7. BPM1 molecular mechanism. 


\section{SUPPLEMENTAL MATERIALS}

\section{SUPPLEMENTARY TABLES}

Table S1. Primer sequences of genes analyzed by RT-qPCR.

\begin{tabular}{|c|c|c|}
\hline GENE & STRAND & PRIMER SEQUENCE \\
\hline \multirow[t]{2}{*}{ BPM1 (AT5G19000.1, AT5G19000.3) } & FW & CCCGGTTGCACTGAATGGGA \\
\hline & REV & ACGATTCATTGTACTTGCTAGATCCGATT \\
\hline \multirow[t]{2}{*}{ BPM1.2 (AT5G19000.2) } & FW & TGCATAACGATAGAAGACATGG \\
\hline & REV & AATGGAGCAATACCTTATCCCG \\
\hline \multirow[t]{2}{*}{ BPM2 (AT3G06190) } & FW & TCTATCCGGGTAATAAGATCGAAGA \\
\hline & REV & CCTTGGAAACCCTAATTGTGTC \\
\hline \multirow[t]{2}{*}{ BPM3 (AT2G39760) } & FW & AGTGATAGACGACATCGAACCT \\
\hline & REV & CAAGGTCATAGAGGTCAGCA \\
\hline \multirow[t]{2}{*}{ BPM4 (AT3G03740) } & FW & GAAGTTACTGACATGGAGCCT \\
\hline & REV & CACTGACTCGCACATTAGAC \\
\hline \multirow[t]{2}{*}{ BPM5 (AT5G21010) } & FW & AAAGGCGTATCAGTCAAATCC \\
\hline & REV & TGTTGGTAAGCGTCTGTCTC \\
\hline \multirow[t]{2}{*}{ BPM6 (AT3G43700) } & FW & GAACAACAGCGACGTAGTGA \\
\hline & REV & CGGACGGCCTTAATAGGTCA \\
\hline \multirow[t]{2}{*}{ GFP } & FW & AAGCTGACCCTGAAGTTCATCTGC \\
\hline & REV & GGTGCGCTCCTGGACGTA \\
\hline \multirow[t]{2}{*}{ EXP (AT4G26410) } & FW & GAGCTGAAGTGGCTTCAATGAC \\
\hline & REV & GGTCCGACATACCCATGATCC \\
\hline \multirow[t]{2}{*}{ TIP4.1 (AT2G25810) } & FW & GTGAAAACTGTTGGAGAGAAGCAA \\
\hline & REV & TCAACTGGATACCCTTTCGCA \\
\hline
\end{tabular}

Table S2. BPM1 overexpressors (L003 and L104) flower significantly earlier than wild type (COL) plants (n=10).

\begin{tabular}{ccc} 
& Days to bolting & Leaf no.at bolting \\
\hline COL & $27.5 \pm 1.5$ & $8.5 \pm 0.8$
\end{tabular}




$\begin{array}{lll}\text { L003 } & 24.9 \pm 3.1^{*} & 7.0 \pm 0.8^{*} \\ \text { L104 } & 25.0 \pm 3.2^{*} & 6.5 \pm 0.9^{*}\end{array}$

*Significantly different from COL $p<0.05$ 

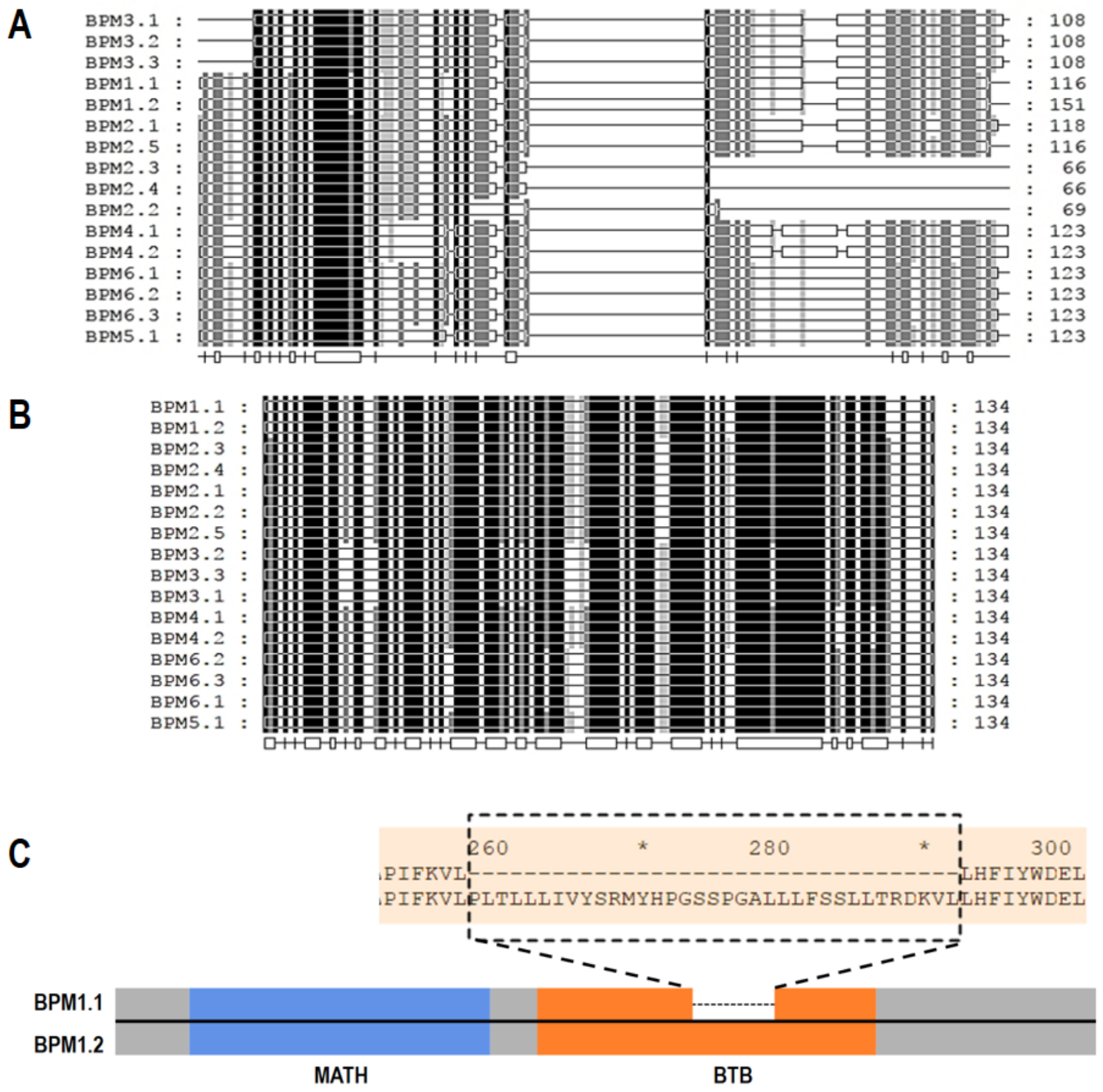

Figure S1. BPM proteins similarity.

Multiple sequence alignments of (A) BTB and (B) MATH domains of 16 known BPM proteins

(www.uniprot.org). In the protein name, the number after decimal point represents a splicing variant.

The number at the end of each sequence represents the number of amino acid residues assumed to comprise the MATH, or BTB domain according to Pfam database. The black and grey boxes represent identical and similar amino acids, respectively. C) Schematic representation of BPM1.1 and BPM1.2 protein sequences, with a detailed view of 35 amino acids within the BTB domain specific for the BPM1.2 variant. 

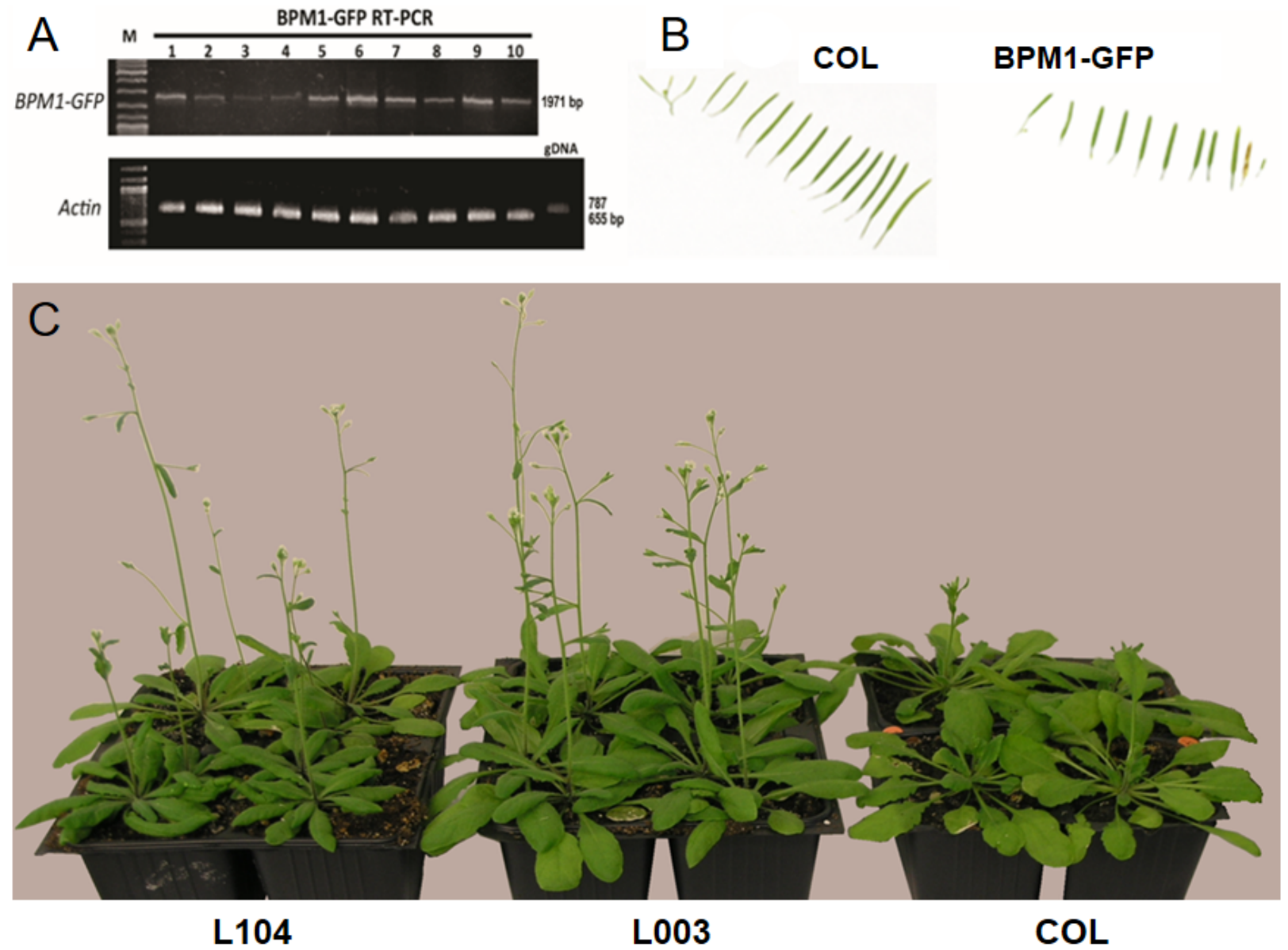

Figure S2. BPM1-GFP transgene expression and early flowering phenotype of transgenic $A$. thaliana plants

A) Expression of BPM1-GFP transgene in 10 lines transformed with BPM1-GFP gene under 35S promoter. mRNA is extracted from leaves of T1 transformants and analyzed by RT-PCR. Actin 3 gene was used as positive control.

B) Shorter siliques of BPM1-GFP overexpressor line L104 compared to wild type (COL)

C) BPM1-GFP overexpressing lines L104 and L003 exhibit early flowering phenotype compared to wild type (COL). 


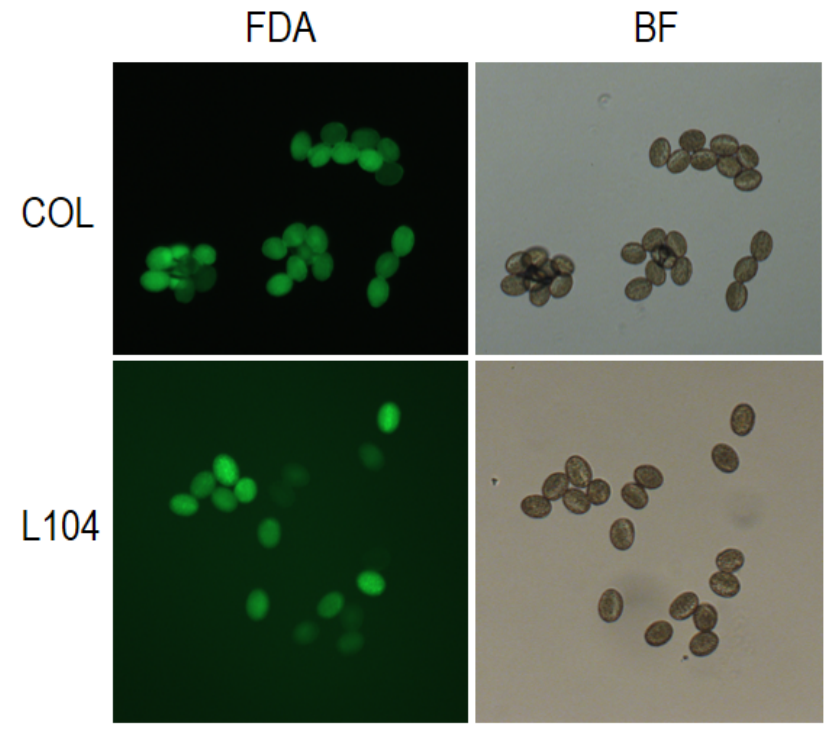

Figure S3. Pollen viability determinate by fluorescein diacetate (FDA) in wild type (COL) and line L104 lines with BPM1 overexpression. 


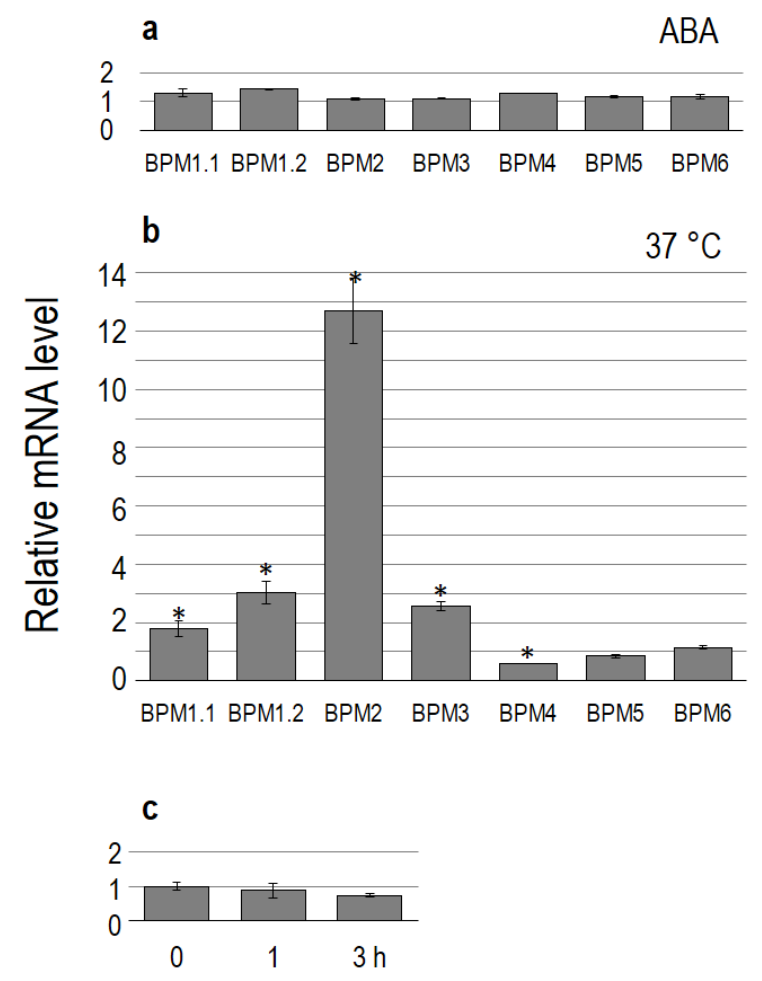

Figure S4. Quantitative gene expression of BPMs after ABA or heat treatment

Relative expression levels of BPM genes are obtained by RT-qPCR in 12-day-old seedlings treated with ABA or exposed to $24^{\circ} \mathrm{C}$ and $37^{\circ} \mathrm{C}$. Geometric means $\pm S D$ of three replicates are shown. Asterisks indicate statistically significant differences between the BPM1 overexpressing lines and wild type seedlings according to Student's $t$-test, $\mathrm{P}<0.01$. Similar results are obtained in three independent experiments.

A) Relative expression levels of endogenous BPM1.1, BPM1.2, BPM2, BPM3, BPM4, BPM5, BPM6 genes in wild type seedlings exposed 3 hours to $50 \mu \mathrm{M}$ ABA. Expressions are normalized to BPMs expression of untreated seedlings.

B) Relative expression levels of endogenous BPM1.1, BPM1.2, BPM2, BPM3, BPM4, BPM5, BPM6 genes in wild type seedlings exposed 3 hours to $37^{\circ} \mathrm{C}$. Expressions are normalized to BPMs expression of control seedlings exposed to $24^{\circ} \mathrm{C}$.

C) Expression of BPM1-GFP transgene remains unchanged at $37^{\circ} \mathrm{C}$ compared to expression at $24^{\circ} \mathrm{C}$. Seedlings of BPM1-GFP overexpressing line L104 are harvested before treatment (0) and 1 and 3 hours after incubation at $37^{\circ} \mathrm{C}$. BPM1-GFP transgene amount was measured by RT-qPCR and normalized to untreated control at $24^{\circ} \mathrm{C}$. 


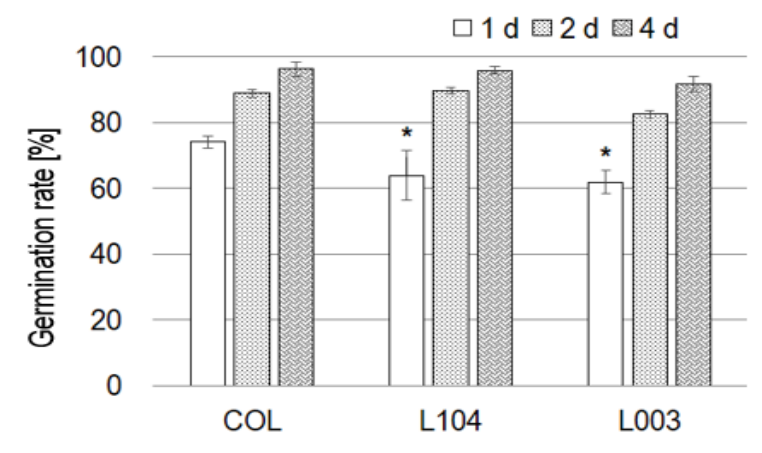

Figure S5. Germination rate (percentage of seeds with radicle emergence) time scale for wild type (COL) and lines with BPM1 overexpression (L104 and L003). Error bars represent standard deviation.

* mark significantly different germination rate comparing to wild type $(P<0.01)$. 


\section{SUPLEMENTARY MOVIE}

In transgenic seedlings transformed with 35S:BPM1-GFP transgene distribution of BPM1-GFP was mainly in the nucleus, except in root elongation zone where BPM1-GFP form differentially sized mobile cytoplasmic particles of unknown origin and function. Roots of 12-day-old L104 seedlings are stained with propidium iodide and subjected to confocal microscopy. 